\title{
Prognostic Value of Preoperative Serum Leucine Aminopeptidases in Hepatocellular Carcinoma Patients Who Underwent Liver Transplantation
}

This article was published in the following Dove Press journal: Cancer Management and Research

\author{
Qingqi Ren ${ }^{1, *}$ \\ Shunjun $\mathrm{Fu}^{2, *}$ \\ Dongping Wang ${ }^{3-5}$ \\ Weiqiang $\mathrm{Ju}^{3-5}$ \\ Xiaoshun $\mathrm{He}^{3-5}$ \\ 'Department of Hepatobiliary and \\ Pancreatic Surgery, Peking University \\ Shenzhen Hospital, Shenzhen, People's \\ Republic of China; ${ }^{2}$ Department of \\ Hepatobiliary Surgery, Zhujiang Hospital, \\ Southern Medical University, Guangzhou, \\ People's Republic of China; ${ }^{3}$ Organ \\ Transplant Center, The First Affiliated \\ Hospital, Sun Yat-sen University, \\ Guangzhou, People's Republic of China; \\ ${ }^{4}$ Guangdong Provincial Key Laboratory of \\ Organ Donation and Transplant \\ Immunology, The First Affiliated Hospital, \\ Sun Yat-sen University, Guangzhou, \\ People's Republic of China; ${ }^{5}$ Guangdong \\ Provincial International Cooperation \\ Base of Science and Technology (Organ \\ Transplantation), The First Affiliated \\ Hospital, Sun Yat-sen University, \\ Guangzhou, People's Republic of China
}

*These authors contributed equally to this work
Correspondence: Xiaoshun He; Weiqiang Ju

Organ Transplant Center, The First Affiliated Hospital, Sun Yat-sen University, No. 58, ZhongShan Road II, Yuexiu, Guangzhou, 510080 Guangdong, People's Republic of China

Email gdtrc@163.com; weiqiangju@।63. com
Background: Leucine aminopeptidases (LAPs) have been reported to be involved in tumor cell proliferation, invasion and angiogenesis. However, the relationship between serum leucine aminopeptidases and prognosis of hepatocellular carcinoma (HCC) patients who underwent liver transplantation (LT) was not yet reported. We aimed to evaluate the prognostic value of preoperative serum leucine aminopeptidases in these patients.

Methods: Clinical data of 106 HCC patients who underwent LT were retrospectively analyzed. The sex ratio, age, HBV infection, Child-Pugh stage, preoperative tumor therapy, AFP, the largest tumor size, tumor number, Edmondson grading, macro- and micro-vascular invasion of patients with different serum LAP level and compositions of patients who met the criteria of Milan, UCSF or Hangzhou were compared using the chi-square test. The Kaplan-Meier method was performed in survival analysis and the log rank test was used in survival comparison.

Results: Serum LAPs were correlated with alpha-fetoprotein (AFP), the largest tumor size, tumor number and macro-vascular invasion. Patients with serum LAPs $>87 \mathrm{U} / \mathrm{L}$ showed significantly poorer disease-free survival (DFS) and overall survival (OS) than those with serum LAPs $\leq 87 \mathrm{U} / \mathrm{L}$. Univariate analysis indicated that serum LAPs, AFP, the largest tumor size, tumor number, and macro- and micro-vascular invasion were all associated with DFS and OS. Multivariate analysis showed that serum LAPs, macro-vascular invasion and the largest tumor size were independently correlated with DFS and OS. Serum LAPs could also distinguish prognosis between patients with different status of AFP, the largest tumor size, tumor number, and macro- and micro-vascular invasion, as well as patients within and beyond selection criteria, such as Milan, University of California, San Francisco and Hangzhou criteria.

Conclusion: Elevated preoperative serum LAPs were associated with advanced tumor stage and aggressive biological behavior, and thus a poor outcome, which could be a prognostic marker for HCC patients who underwent LT.

Keywords: leucine aminopeptidases, hepatocellular carcinoma, liver transplantation, disease-free survival, overall survival

\section{Introduction}

Liver cancer was the sixth most common cancer worldwide in terms of 792,000 new diagnosed cases, and the third most common cause of death from cancer $(818,000$ deaths annually). ${ }^{1}$ Despite the progress of hepatitis B virus (HBV) vaccine prevention and treatment options for liver cancer, the cancer burden is increasing owing to the population growing and aging. ${ }^{1}$ Eighty-six percent of liver cancer occurred in developing countries 
and $90 \%$ were hepatocellular carcinoma (HCC). ${ }^{2}$ Nowadays, liver transplantation (LT) has been one of the options to cure HCC radically accompanied by liver resection, radiofrequency ablation, microwave ablation, percutaneous ethanol injection and so on. $^{3}$ Compared with other radical treatment, LT removed the cirrhotic liver $^{4}$ and a well-controlled HBV recurrence, ${ }^{5}$ patients could benefit more from this operation theoretically and practically. ${ }^{6-9}$ However, there are still a proportion of HCC patients who underwent LT suffering from tumor recurrence even when they met the selection criteria, such as Milan criteria, ${ }^{10}$ University of California, San Francisco (UCSF) criteria $^{11}$ and Hangzhou criteria. ${ }^{12}$

Because of the organ shortage for LT, it is increasingly important to achieve the maximum benefit of LT for HCC patients. Previously, some studies have proven the deficiency of the well-acknowledged criteria, including Milan criteria, UCSF criteria and Hangzhou criteria, and some new combined criteria had been brought up. ${ }^{13-18}$ Some of these combined criteria included objective biological criteria, irrelevant to age, gender, pathology and so on, so they are more reproducible. ${ }^{13,14,19}$ On the other hand, the criteria for the diagnosis of HCC have improved as well and serum enzymes are taking an increasingly important part. Leucine aminopeptidases (LAPs), a diverse set of exopeptidases, catalyze the hydrolysis of leucine residues from the amino-termini of protein or peptide substrates. ${ }^{20}$ To be mentioned, LAPs have distinct substrate specificities beyond Leu hydrolysis with different temperature, $\mathrm{pH}$ and divalent cation requirements. Some LAPs could act as transcription factors, participate in specific recombination or interact with key membrane transporters. ${ }^{21}$ They have been demonstrated in most human tissues and high activities in the liver, duodenum, small intestine, pancreas, testis and stoma cells of the uterus. ${ }^{22}$ LAPs also have been reported related to malignant cell proliferation, invasion and angiogenesis, ${ }^{21,23,24}$ and implicated in the pathological disorder of livers. ${ }^{21,23,25}$ Besides, the expression of LAPs is interrelated to prognosis and malignant development of HCC. ${ }^{26,27}$ However, the prognostic value of serum LAPs on patients with HCC who underwent liver transplantation has not been reported. We aimed to evaluate the prognostic value of preoperative serum leucine aminopeptidases in these patients.

\section{Patients and Methods}

All the preoperative clinical data of HCC patients who underwent liver transplantation at the Organ Transplant Center, the First Affiliated Hospital, Sun Yat-sen University from March, 2005 to October, 2013 were collected. Patients with hepatorenal syndrome on hemodialysis, uncontrolled severe infection, HIV infection, other uncured malignant tumor, HCC metastases beyond the liver, hepatic and portal vein invasion and without preserved lung and cardiac function to tolerate LT were excluded from the waiting list. The diagnosis was confirmed through hematoxylin-eosin staining and immunohistochemistry (when necessary) by at least two pathologists. All the patients received deceased donor liver transplantation. All organs were donated voluntarily with written informed consent, and this was conducted in accordance with the Declaration of Istanbul. The retrospective study was approved by the medical ethic committee of the First Affiliated Hospital, Sun Yat-sen University in compliance with the Declaration of Helsinki, and the ethic approval number was [2016]081. Due to the retrospective nature of the study, written informed consent was waived. Data confidentiality was assured by storage of patient identifiers in separate encrypted files and the files were accessible only to the research team offline. Only the patients with complete preoperative clinical, laboratory, imaging and follow-up data were selected. The general status of patients, such as gender, age, HBsAg, Child-Pugh stage and preoperative tumor therapy, was used to evaluate the comparability between groups, and tumor-related markers, such as serum AFP, the largest tumor size, tumor number, Edmondson grading, and macro- and micro-vascular invasion, were compared between patients with different LAP levels.

\section{Experimental Design}

The patients were classified based on the cutoff value, which was selected using the receiver operating characteristic (ROC) curve analysis. A combination of Milan criteria or UCSF criteria or Hangzhou criteria and LAP cutoff value were used to classify HCC patients into four groups: patients who met the criteria and LAP level below the cutoff value, patients who met the criteria and LAP level above the cutoff value, patients beyond the criteria and LAP level below the cutoff value, and patients beyond the criteria and LAP level above the cutoff value.

\section{Treatment and Follow-Up}

All the patients received modified piggy-back orthotopic liver transplantation or classic orthotopic liver transplantation. Perioperative treatment and follow-up were as described previously. ${ }^{28}$ Briefly, two doses of $20 \mathrm{mg}$ basiliximab (Simulect, Novartis Pharma AG, Basel, Switzerland) were given intraoperatively and the fourth day after surgery. Mycophenolate mofetil (MMF) and FK506 were used post surgery to prevent organ rejection. The concentration of 
FK506 was tested routinely and adjusted according to the test results and serum liver enzyme level, and the serum creatinine level was also taken into consideration. Blood routine tests, liver enzyme level, and serum tests of hepatic and renal function were performed at each follow-up, and also for serum AFP level and liver ultrasound test. An abdominal CT scan was performed every 6 months. Clinical and radiological manifestations of tumor, with or without pathological diagnosis, ${ }^{29}$ were defined as tumor recurrence. As for the patients suffering from recurrence, radiofrequency ablation (RFA), transarterial chemoembolization (TACE), sorafenib administration, tumor resection and chemotherapy were chosen based on the patient's specific condition.

\section{Statistical Analysis}

Statistical analysis was performed using SPSS software (Windows Version 16.0; SPSS Inc., Chicago, IL, USA). The ROC curve analysis was used to determine the optimal cutoff value of LAPs. The demographic and clinicopathological data were compared between HCC patients with low and high LAP values using the chi-square test. Survival analysis was performed using the Kaplan-Meier method and compared using the log rank test. A multivariate Cox regression model using a forward (conditional) method was used to identify independent risk factors that affected patients' survival. $P$ value less than 0.05 was considered statistically significant.

\section{Results}

\section{Clinicopathological Characteristics of Patients}

A total of $106 \mathrm{HCC}$ patients were enrolled in this study, including 100 male patients and 6 female patients with a median age of 49 (range from 13 to 66) years. Median follow-up time was 38 months. Half of these patients suffered from tumor recurrence, and 40 patients died of tumor progression. One hundred and one out of the 106 patients were infected by HBV. According to the ChildPugh score system, 67 patients were within Child-Pugh stage A, and 29 and 10 for Child-Pugh stage B and C, separately (Supplementary Table 1). Forty-nine patients received preoperative therapy, such as hepatectomy, radiofrequency ablation and transcatheter arterial chemoembolization (Supplementary Table 2). There were 67 patients of grading I-II and 39 patients of grading III-IV according to Edmondson-Steiner grading. Moreover, patients were classified through three well accepted criteria: Milan criteria, UCSF criteria and Hangzhou criteria. Thirtyseven patients fulfilled the Milan criteria, 56 patients for UCSF criteria and 66 patients for Hangzhou criteria.

\section{The Determination of Serum LAP Cutoff Value and Its Sensitivity and Specificity}

The best cutoff value of serum LAPs was $87 \mathrm{U} / \mathrm{L}$ by the ROC curve (Supplement Figure 1), and the sensitivity and specificity were 0.736 and 0.755 (the area under the ROC curve: 0.788 , 95\% confidence interval: $0.699-0.877, P<0.001$ ), separately.

\section{Clinical Character of Hepatocellular Carcinoma Patients with Different Serum LAP Value}

All the enrolled patients were divided into two groups based on the serum LAP cutoff value, and clinical character was compared between groups (Table 1). There was no significant difference in general status between the two groups, such as gender, age, serum hepatitis B virus antigen (HBsAg) positive rate, Child-Pugh classification and preoperative therapy, indicating the comparability between the two groups. Patients with serum LAPs $>87 \mathrm{U} / \mathrm{L}$ tended to have higher serum alphafetoprotein (AFP) level, larger tumor size, more tumor nodules and higher rate of macro-vascular invasion. In addition, patients with serum LAPs $>87 \mathrm{U} / \mathrm{L}$ tended to exceed the Milan, UCSF and Hangzhou criteria.

\section{Disease-Free Survival and Overall Survival Comparison Between Patients with Different Serum LAP Value}

The prognosis of HCC patients with different levels of serum LAPs was evaluated using Kaplan-Meier survival analysis (Figure 1), and compared using the log rank test. The 1, 3, 5-year DFS rates were significantly poorer for patients with serum LAPs $>87 \mathrm{U} / \mathrm{L}(\mathrm{n}=52)$ than patients with serum LAPs $\leq 87 \mathrm{U} / \mathrm{L}(\mathrm{n}=54)(50.0 \%, 28.8 \%, 19.2 \%$ vs $87.0 \%$, $77.5 \%, 72.1 \%, P<0.001$ ), which was also the same for 1,3 , 5 -year OS rates between the two groups $(71.2 \%, 41.6 \%, 35.8 \%$ vs $98.1 \%, 87.0 \%, 82.3 \%, P<0.001)$. Then, further investigation was performed based on the LAP level. The patients were divided into three groups: group 1, patients with serum LAPs $\leq$ $87 \mathrm{U} / \mathrm{L}(\mathrm{n}=54)$, the cutoff value and which was close to the normal range of serum LAPs $(30 \sim 70 \mathrm{U} / \mathrm{L})$. The other patients were classified into another two groups by the median of serum LAP level (123 U/L), which were group 2 for patients with serum LAPs between 87 and $123 \mathrm{U} / \mathrm{L}(\mathrm{n}=27)$ and group 3 for 
Table I Comparison of Clinical Character Between HCC Patients Who Underwent Liver Transplantation with Different Serum LAPs

\begin{tabular}{|c|c|c|c|c|c|}
\hline \multirow[t]{2}{*}{ Category } & \multirow[t]{2}{*}{ Subcategory } & \multirow[t]{2}{*}{ Cases } & \multicolumn{2}{|c|}{ LAPs (U/L) } & \multirow[t]{2}{*}{$P$ value } \\
\hline & & & $\begin{array}{l}\leq 87 \\
(n=54)\end{array}$ & $\begin{array}{l}>87 \\
(n=52)\end{array}$ & \\
\hline \multirow[t]{2}{*}{ Gender } & Male & 100 & 49 & 51 & \\
\hline & Female & 6 & 5 & 1 & 0.102 \\
\hline \multirow[t]{2}{*}{ Age (years) } & $\leq 50$ & 56 & 27 & 29 & \\
\hline & $>50$ & 50 & 27 & 23 & 0.552 \\
\hline \multirow{2}{*}{$\mathrm{HBsAg}$} & Positive & 101 & 51 & 50 & \\
\hline & Negative & 5 & 3 & 2 & 0.678 \\
\hline \multirow[t]{3}{*}{ Child-Pugh stage } & A & 67 & 35 & 32 & \\
\hline & B & 29 & 15 & 14 & \\
\hline & C & 10 & 4 & 6 & 0.767 \\
\hline \multirow{2}{*}{$\begin{array}{l}\text { Preoperative } \\
\text { tumor therapy }\end{array}$} & Yes & 49 & 26 & 23 & \\
\hline & No & 57 & 28 & 29 & 0.686 \\
\hline \multirow[t]{2}{*}{$\operatorname{AFP}(\mathrm{ng} / \mathrm{mL})$} & $\leq 400$ & 69 & 44 & 25 & \\
\hline & $>400$ & 37 & 10 & 27 & $<0.001$ \\
\hline \multirow{3}{*}{$\begin{array}{l}\text { The largest tumor } \\
\text { size }(\mathrm{cm})\end{array}$} & $\leq 5$ & 61 & 41 & 20 & \\
\hline & 5 to 8 & 19 & 7 & 12 & \\
\hline & $>8$ & 26 & 6 & 20 & $<0.001$ \\
\hline \multirow[t]{2}{*}{ Tumor number } & $\leq 3$ & 74 & 43 & 31 & \\
\hline & $>3$ & 32 & 11 & 21 & 0.025 \\
\hline \multirow{2}{*}{$\begin{array}{l}\text { Edmondson } \\
\text { grading }\end{array}$} & I-II & 67 & 36 & 31 & \\
\hline & III-IV & 39 & 18 & 21 & 0.452 \\
\hline \multirow{2}{*}{$\begin{array}{l}\text { Macro-vascular } \\
\text { invasion }\end{array}$} & Yes & 27 & 5 & 22 & \\
\hline & No & 79 & 49 & 30 & $<0.001$ \\
\hline \multirow{2}{*}{$\begin{array}{l}\text { Micro-vascular } \\
\text { invasion }\end{array}$} & Yes & 13 & 3 & 10 & \\
\hline & No & 93 & 42 & 51 & 0.131 \\
\hline \multirow[t]{2}{*}{ Milan criteria } & Within & 37 & 30 & 7 & \\
\hline & Beyond & 69 & 24 & 45 & $<0.001$ \\
\hline \multirow[t]{2}{*}{ UCSF criteria } & Within & 56 & 39 & 17 & \\
\hline & Beyond & 50 & 15 & 35 & $<0.001$ \\
\hline \multirow[t]{2}{*}{ Hangzhou criteria } & Within & 66 & 45 & 21 & \\
\hline & Beyond & 40 & 9 & 31 & $<0.001$ \\
\hline
\end{tabular}

patients with serum LAPs $>123 \mathrm{U} / \mathrm{L}(\mathrm{n}=25)$. The patients' DFS and OS were also analyzed through the Kaplan-Meier method and compared using the log rank test. The 1,3,5-year DFS rates for patients in group 1 were $87.0 \%, 77.5 \%$ and $72.1 \%$, separately, $66.7 \%, 44.4 \%$ and $38.1 \%$ for group 2 patients, and $32.0 \%, 12.0 \%$ and $6.0 \%$ for group 3 patients. All the $P$ values between any two groups were less than 0.05 (0.002 for group 1 vs group $2,<0.001$ for group 1 vs group 3 and 0.003 for group 2 vs group 3). Accordingly, the 1, 3, 5-year OS rates were $98.1 \%, 87.0 \%$ and $82.3 \%$ for group $1,81.5 \%$, $57.6 \%$ and 52.8 for group 2 , and $60.0 \%, 23.0 \%$ and $17.2 \%$ for group 3, separately. All the differences between groups were also statistically significant $(0.006$ for group 1 vs group 2 , $<0.001$ for group1 vs group 3 and 0.005 for group 2 vs group 3). A bivariate analysis using Pearson's correlation was conducted to evaluate the correlation between serum LAPs and DFS or OS, and found that the correlation coefficient between LAPs and DFS was $-0.417(P<0.001)$, and -0.375 for LAPs and OS $(P<0.001)$. Besides the prognostic value of serum LAPs, there was also a negative correlation between its level and prognosis; the higher the serum LAP value, the worse the prognosis.

\section{Clinicopathological Data on Patients' Prognosis}

Univariate analysis indicated that serum LAPs, AFP level, the largest tumor size, tumor number, macro-vascular invasion and micro-vascular invasion were all related with patients' prognosis (Table 2). HCC patients with AFP $>400 \mathrm{ng} / \mathrm{mL}$, the larger tumor size, tumor number $>3$, macro-vascular invasion and micro-vascular invasion had a significant worse outcome than those without such characters. Then, the positive variables were added to the multivariate Cox regression model directly, except for the variable the largest tumor size, which was added after being transformed as the largest tumor size $\leq$ $5 \mathrm{~cm}$ or $>5 \mathrm{~cm}$ and $\leq 8 \mathrm{~cm}$ or $>8 \mathrm{~cm}$, to screen the independent risk factor on patients' prognosis. Macrovascular invasion, the largest tumor size $>5 \mathrm{~cm}$ and serum LAP level $>87 \mathrm{U} / \mathrm{L}$ were independent factors that significantly affected patients' prognosis (Table 3 ).

As previous described, the AFP level, the largest tumor size, tumor number, macro-vascular invasion and microvascular invasion, along with LAP level, were related with patients' prognosis, and then we evaluated the distinguishing value of serum LAPs in patients with or without these conditions using the Kaplan-Meier method and compared using the log rank test.

\section{Distinguishing Effect of LAPs in HCC Patients with Different Level of AFP}

For patients with AFP $\leq 400 \mathrm{ng} / \mathrm{mL}$, the 1, 3, 5-year DFS rates were significantly poorer for these with serum LAPs $>87 \mathrm{U} / \mathrm{L}$ $(\mathrm{n}=25)$ than those with serum LAPs $\leq 87 \mathrm{U} / \mathrm{L}(\mathrm{n}=44)(72.0 \%$, $52.0 \%, 34.7 \%$ vs $88.6 \%, 79.2 \%, 72.5 \%, P=0.017$ ), which was the same for patients' OS rates $(80.0 \%, 62.1 \%, 56.5 \%$ vs $100 \%, 88.6 \%, 85.8 \%, P=0.009$ ). Accordingly, for patients with AFP $>400 \mathrm{ng} / \mathrm{mL}$, the 1, 3, 5-year DFS rates were also poorer for these with serum LAPs $>87 \mathrm{U} / \mathrm{L}(\mathrm{n}=27)$ than those 
Survival Functions

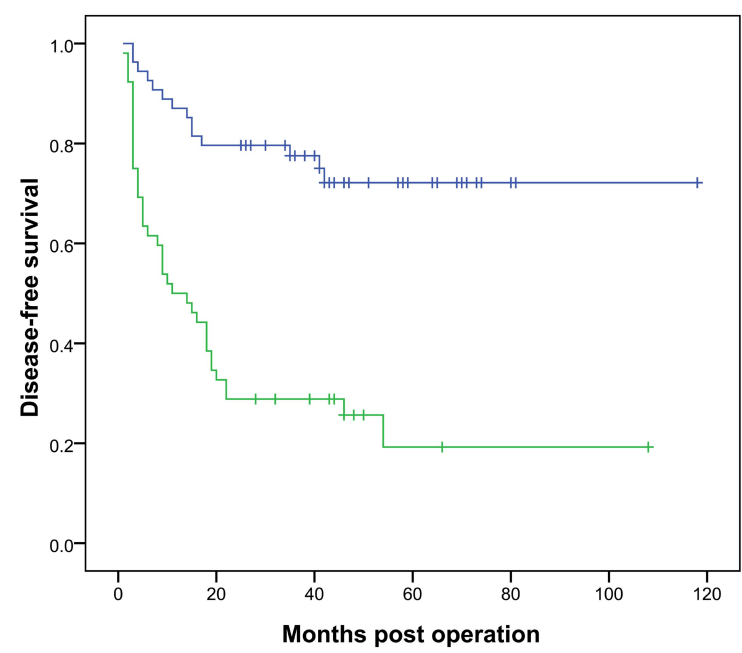

Survival Functions

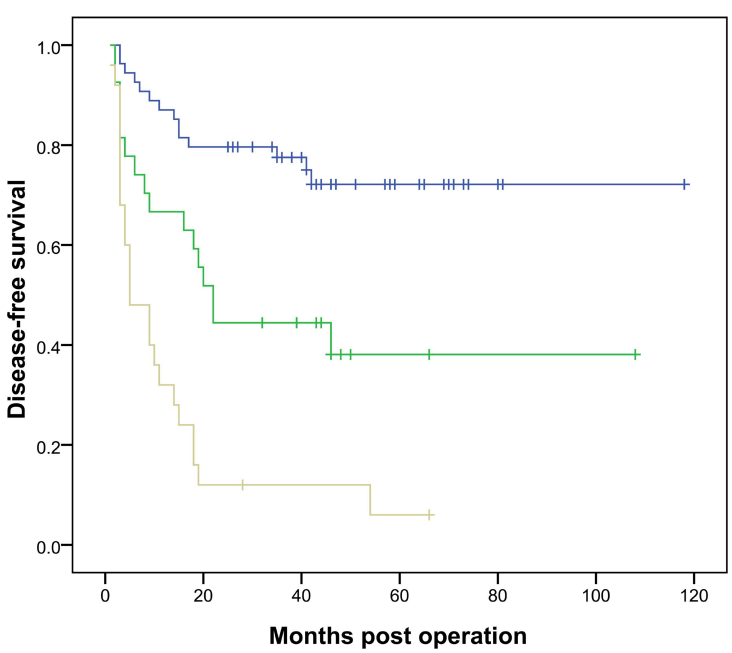

Survival Functions

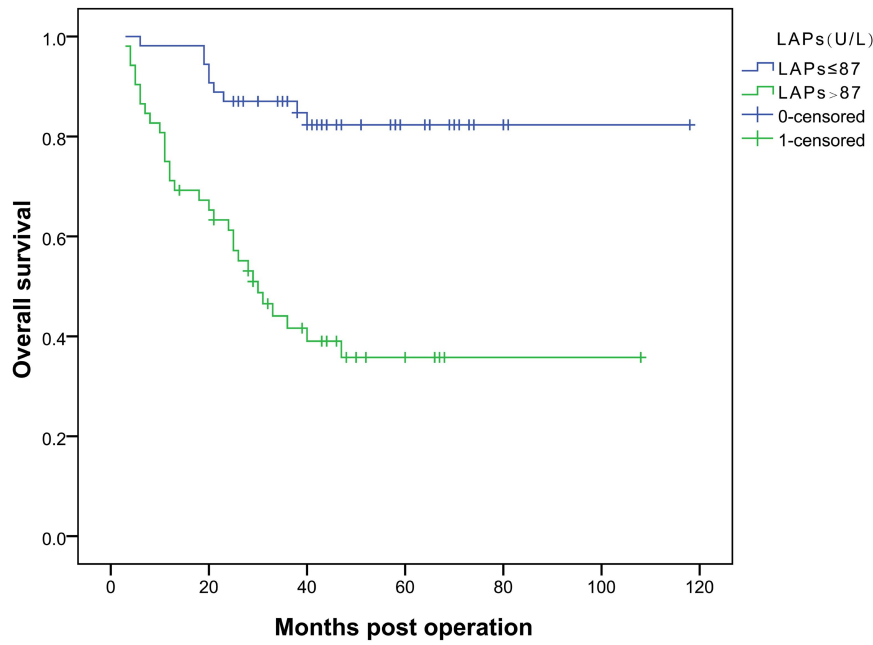

Survival Functions

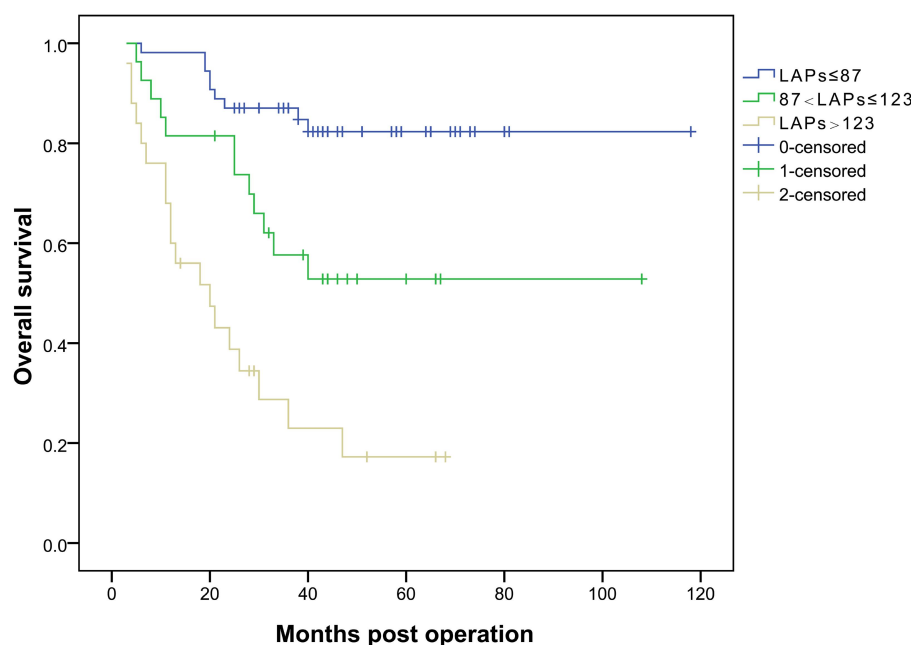

Figure I DFS and OS for HCC patients who underwent liver transplantation with different levels of serum LAPs. DFS and OS of patients with lower serum LAPs were significantly better than those with higher serum LAPs.

with serum LAPs $\leq 87 \mathrm{U} / \mathrm{L}(\mathrm{n}=10)(29.6 \%, 7.4 \%, 3.7 \%$ vs $80.0 \%, 70.0 \%, 70.0 \%, P<0.001)$, and also there was the same condition in OS comparison $(70.4 \%, 21.5 \%, 17.2 \%$ vs $90.0 \%$, $80.0 \%, 68.6 \%, P=0.009$ ) (Figure 2).

\section{Distinguishing Effect of LAPs in HCC Patients with Different Size of the Largest Tumor}

As previously described, the largest tumor size $>5 \mathrm{~cm}$ was the independent risk factor on patients' prognosis, and then we investigated the prognostic value of serum LAPs in patients with different tumor size. For patients with the largest tumor size $\leq 5 \mathrm{~cm}$, the $1,3,5$-year DFS rates were significantly poorer in patients with serum LAPs $>87 \mathrm{U} / \mathrm{L}(\mathrm{n}=20)$ than in those with serum LAPs $\leq 87 \mathrm{U} / \mathrm{L}(\mathrm{n}=41)(80.0 \%, 50.0 \%$, $50.0 \%$ vs $90.2 \%, 87.8 \%, 80.7 \%, P=0.007$ ), which was also similar in patients' 1, 3, 5-year OS rates $(95.0,64.9 \%, 56.8 \%$ vs $97.6 \%, 95.1 \%, 95.1 \%, P=0.001)$. For patients with the largest tumor size $>5 \mathrm{~cm}$, the 1, 3, 5-year DFS rates were significantly poorer for those with serum LAPs $>87 \mathrm{U} / \mathrm{L}$ ( $\mathrm{n}=$ 32) than those with serum LAPs $\leq 87 \mathrm{U} / \mathrm{L}(\mathrm{n}=13)(31.2 \%$, $15.6 \%, 7.8 \%$ vs $76.9 \%, 46.2 \%, 46.2 \%, P=0.008)$. There was the same trend in patients' $1,3,5$-year OS rates $(95.0,64.9 \%$, $56.8 \%$ vs $97.6 \%, 95.1 \%, 95.1 \%, P=0.095)$, but not statistically significant (Figure 3). 
Table 2 Clinicopathological Variables Affecting Prognosis in HCC Patients Who Underwent Liver Transplantation

\begin{tabular}{|c|c|c|c|c|c|c|c|c|c|}
\hline \multirow[t]{2}{*}{ Variables } & \multirow[t]{2}{*}{$\mathbf{n}$} & \multicolumn{4}{|l|}{ DFS } & \multicolumn{3}{|l|}{ OS } & \multirow[b]{2}{*}{$P$} \\
\hline & & I-Yr & $3-\mathbf{Y r}$ & $5-Y r$ & $P$ & $\mathrm{I}-\mathbf{Y r}$ & $3-\mathbf{Y r}$ & $5-\mathbf{Y r}$ & \\
\hline \multicolumn{10}{|l|}{ Age (years) } \\
\hline$\leq 50$ & 56 & $62.5 \%$ & $47.9 \%$ & $43.3 \%$ & & $78.6 \%$ & $58.2 \%$ & $52.8 \%$ & \\
\hline$>50$ & 50 & $76.0 \%$ & $60.0 \%$ & $50.6 \%$ & 0.225 & $92.0 \%$ & $73.0 \%$ & $67.2 \%$ & 0.121 \\
\hline \multicolumn{10}{|l|}{ Child-Pugh stage } \\
\hline A & 67 & $64.2 \%$ & $46.1 \%$ & $37.1 \%$ & & $82.1 \%$ & $60.6 \%$ & $54.2 \%$ & \\
\hline B & 29 & $75.9 \%$ & $62.1 \%$ & $55.9 \%$ & & $89.7 \%$ & $70.2 \%$ & $65.1 \%$ & \\
\hline C & 10 & $80.0 \%$ & $80.0 \%$ & $80.0 \%$ & 0.067 & $80.0 \%$ & $80.0 \%$ & $80.0 \%$ & 0.326 \\
\hline \multicolumn{10}{|l|}{ Preoperative tumor therapy } \\
\hline Yes & 49 & $73.5 \%$ & $50.8 \%$ & $38.6 \%$ & & $87.8 \%$ & $68.6 \%$ & $58.5 \%$ & \\
\hline No & 57 & $64.9 \%$ & $56.1 \%$ & $50.2 \%$ & 0.775 & $82.5 \%$ & $62.2 \%$ & $59.8 \%$ & 0.776 \\
\hline \multicolumn{10}{|l|}{$\operatorname{AFP}(\mathrm{ng} / \mathrm{mL})$} \\
\hline$\leq 400$ & 69 & $82.6 \%$ & $69.3 \%$ & $60.1 \%$ & & $92.8 \%$ & $79.2 \%$ & $75.3 \%$ & \\
\hline$>400$ & 37 & $43.2 \%$ & $24.3 \%$ & $20.3 \%$ & $<0.001$ & $70.3 \%$ & $38.5 \%$ & $31.4 \%$ & $<0.001$ \\
\hline \multicolumn{10}{|l|}{ The largest tumor size $(\mathrm{cm})$} \\
\hline$\leq 5$ & 61 & $86.9 \%$ & $75.4 \%$ & $70.7 \%$ & & $96.7 \%$ & $86.0 \%$ & $83.6 \%$ & \\
\hline 5 to 8 & 19 & $68.4 \%$ & $36.1 \%$ & $24.1 \%$ & & $78.9 \%$ & $57.9 \%$ & $37.1 \%$ & \\
\hline$>8$ & 26 & $26.9 \%$ & $15.4 \%$ & $10.3 \%$ & $<0.001$ & $61.5 \%$ & $23.1 \%$ & $23.1 \%$ & $<0.001$ \\
\hline \multicolumn{10}{|l|}{ Tumor number } \\
\hline$\leq 3$ & 74 & $79.7 \%$ & $67.4 \%$ & $58.8 \%$ & & $86.5 \%$ & $78.1 \%$ & $69.8 \%$ & \\
\hline$>3$ & 32 & $43.8 \%$ & $21.9 \%$ & $17.5 \%$ & $<0.001$ & $81.2 \%$ & $34.9 \%$ & $34.9 \%$ & $<0.001$ \\
\hline \multicolumn{10}{|l|}{ Edmondson grading } \\
\hline I-II & 67 & $71.6 \%$ & $53.4 \%$ & $47.8 \%$ & & $88.1 \%$ & $70.5 \%$ & $60.8 \%$ & \\
\hline III-IV & 39 & $64.1 \%$ & $53.8 \%$ & $44.3 \%$ & 0.817 & $79.5 \%$ & $56.1 \%$ & $56.1 \%$ & 0.285 \\
\hline \multicolumn{10}{|l|}{ Macro-vascular invasion } \\
\hline Yes & 27 & $40.7 \%$ & $7.4 \%$ & $3.7 \%$ & & $66.7 \%$ & $25.9 \%$ & $17.3 \%$ & \\
\hline No & 79 & $78.5 \%$ & $69.6 \%$ & $61.4 \%$ & $<0.001$ & $91.1 \%$ & $80.6 \%$ & $74.3 \%$ & $<0.001$ \\
\hline \multicolumn{10}{|l|}{ Micro-vascular invasion } \\
\hline Yes & 13 & $38.5 \%$ & $7.7 \%$ & $7.7 \%$ & & $69.2 \%$ & $30.8 \%$ & $23.1 \%$ & \\
\hline No & 93 & $73.1 \%$ & $59.1 \%$ & $52.3 \%$ & $<0.001$ & $87.1 \%$ & $70.2 \%$ & $65.0 \%$ & 0.001 \\
\hline \multicolumn{10}{|l|}{ Milan criteria } \\
\hline Within & 37 & $91.9 \%$ & $89.2 \%$ & $84.9 \%$ & & $97.3 \%$ & $94.5 \%$ & $94.5 \%$ & \\
\hline Beyond & 69 & $56.5 \%$ & $345 \%$ & $25.7 \%$ & $<0.001$ & $78.3 \%$ & $49.4 \%$ & $41.3 \%$ & $<0.001$ \\
\hline \multicolumn{10}{|l|}{ UCSF criteria } \\
\hline Within & 50 & $91.1 \%$ & $81.8 \%$ & $79.0 \%$ & & $94.6 \%$ & $91.0 \%$ & $86.2 \%$ & \\
\hline Beyond & 56 & $44.0 \%$ & $22.0 \%$ & $10.9 \%$ & $<0.001$ & $74.0 \%$ & $36.6 \%$ & $30.9 \%$ & $<0.001$ \\
\hline \multicolumn{10}{|l|}{ Hangzhou criteria } \\
\hline Within & 66 & $84.8 \%$ & $78.8 \%$ & $72.0 \%$ & & $92.4 \%$ & $86.1 \%$ & $84.0 \%$ & \\
\hline Beyond & 40 & $42.5 \%$ & $12.5 \%$ & $4.7 \%$ & $<0.001$ & $72.5 \%$ & $30.9 \%$ & $21.7 \%$ & $<0.001$ \\
\hline
\end{tabular}

Distinguishing Effect of LAPs in HCC Patients with Different Tumor Number

For patients with tumor number $\leq 3$, the 1, 3, 5-year DFS rates were significantly poorer for patients with serum LAPs $>87 \mathrm{U} / \mathrm{L}(\mathrm{n}=31)$ than those with serum LAPs $\leq 87 \mathrm{U} / \mathrm{L}(\mathrm{n}=43)(61.3 \%, 45.2 \%, 26.3 \%$ vs $93.0 \%, 83.4 \%, 79.8 \%, P<0.001)$. And it was the same for patients' OS rates $(71.0 \%, 60.2 \%, 49.4 \%$ vs 
Table 3 Independent Risk Factors for Prognosis in HCC Patients Who Underwent Liver Transplantation

\begin{tabular}{|l|l|l|l|l|l|l|}
\hline \multirow{2}{*}{ Variables } & \multicolumn{2}{l|}{ DFS } & \multicolumn{2}{l|}{ OS } \\
\cline { 2 - 7 } & $\mathbf{H R}$ & $\mathbf{9 5 \%} \mathbf{C l}$ & $\mathbf{P}$ & $\mathbf{H R}$ & $\mathbf{9 5 \%} \mathbf{C l}$ & $\mathbf{P}$ \\
\hline Macro-vascular invasion & 2.480 & $1.327-4.633$ & 0.004 & 2.401 & $1.185-4.863$ & 0.015 \\
LAPs & 2.659 & $1.371-5.156$ & 0.004 & 2.479 & $1.100-5.587$ & 0.029 \\
The largest tumor size & 2.514 & $1.306-4.838$ & 0.006 & 3.627 & $1.584-8.301$ \\
\hline
\end{tabular}

$97.7 \%, 90.7 \%, 84.8 \%, P<0.001)$. For patients with $P=0.010)$. And it was the same for patients' OS rates tumor number $>3$, the 1,3 , 5-year DFS rates were $(74.4 \%, 15.4 \%, 15.4 \%$ vs $100 \%, 72.7 \%, 72.7 \%, P=$ significantly poorer for patients with serum LAPs $>$ 0.006) (Figure 4). No matter whether the tumor number $87 \mathrm{U} / \mathrm{L}(\mathrm{n}=21)$ than those with serum LAPs $\leq 87 \mathrm{U} / \mathrm{L}$ was more than 3 , patients with serum LAPs $>87 \mathrm{U} / \mathrm{L}$ $(\mathrm{n}=11)(33.3 \%, 4.8 \%, 4.8 \%$ vs $63.6 \%, 54.5 \%, 40.9 \%$, tended to have a poor prognosis.

Survival Functions

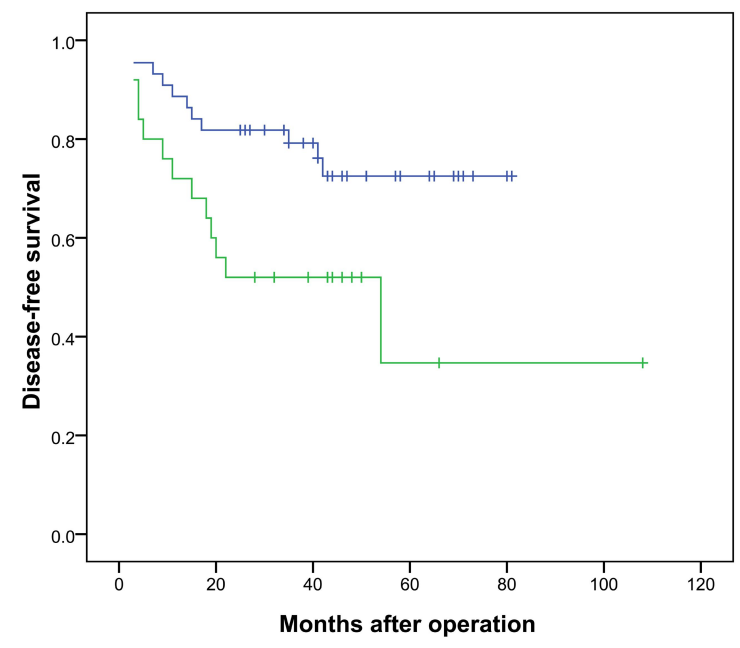

Survival Functions

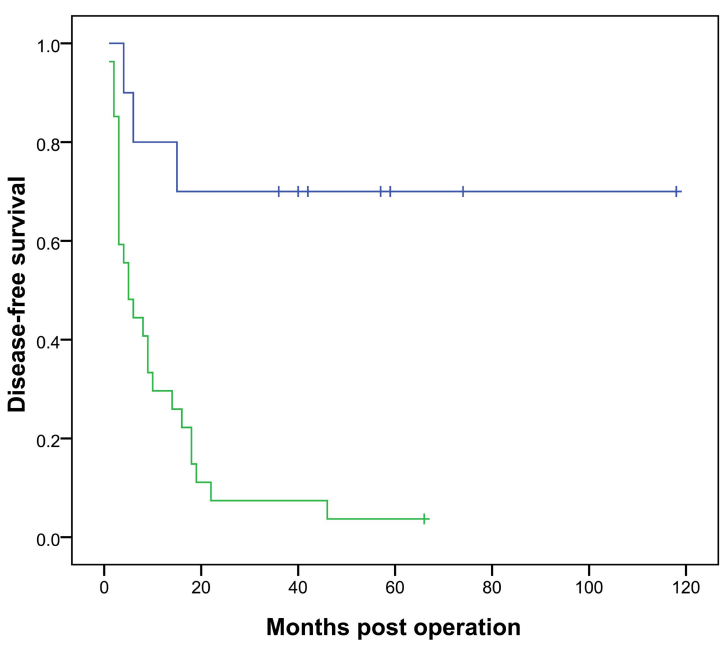

Survival Functions

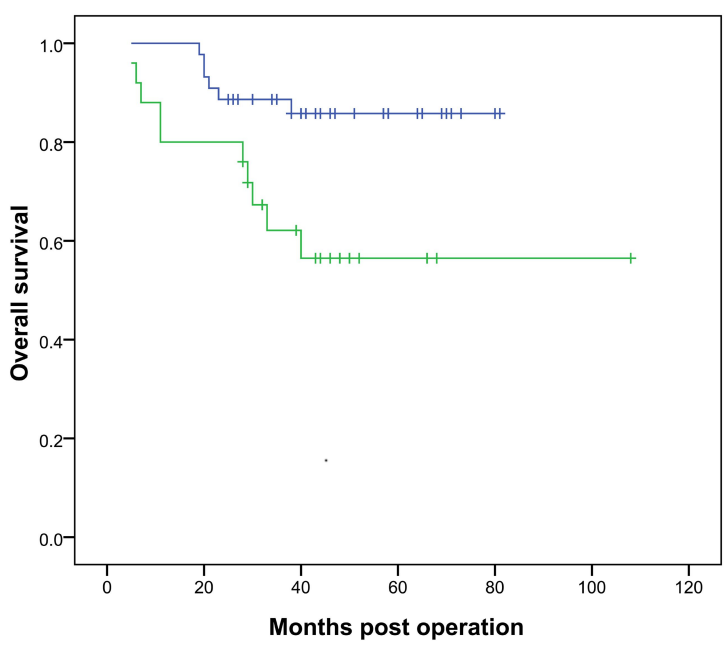

Survival Functions

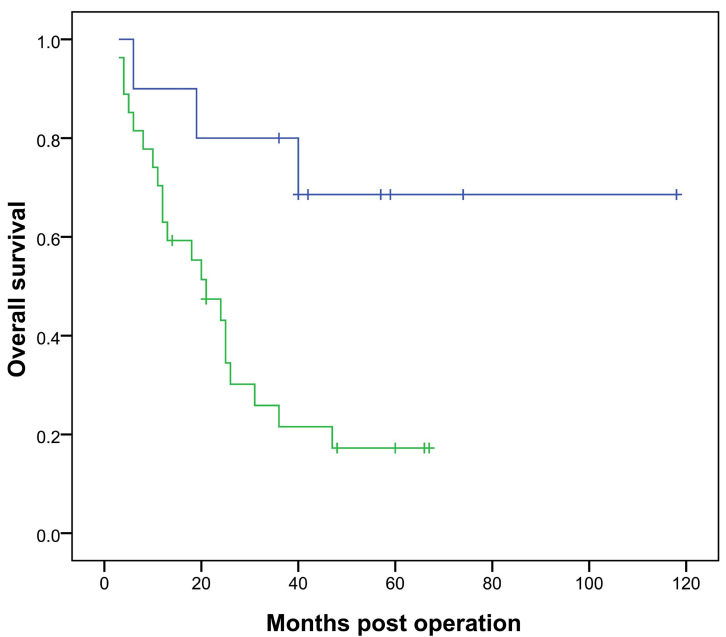

AFP $\leq 400 \mathrm{ng} / \mathrm{ml}$ $\neg$ LAPs $\leq 87 \mathrm{U} / \mathrm{L}$ $\neg$ LAPs $>87 \mathrm{U} / \mathrm{L}$

+
+-censored
1-censored

Figure 2 DFS and OS for HCC patients who underwent liver transplantation with AFP $\leq 400 \mathrm{ng} / \mathrm{mL}$ and $>400 \mathrm{ng} / \mathrm{mL}$ grouped by serum LAP level. 
Survival Functions

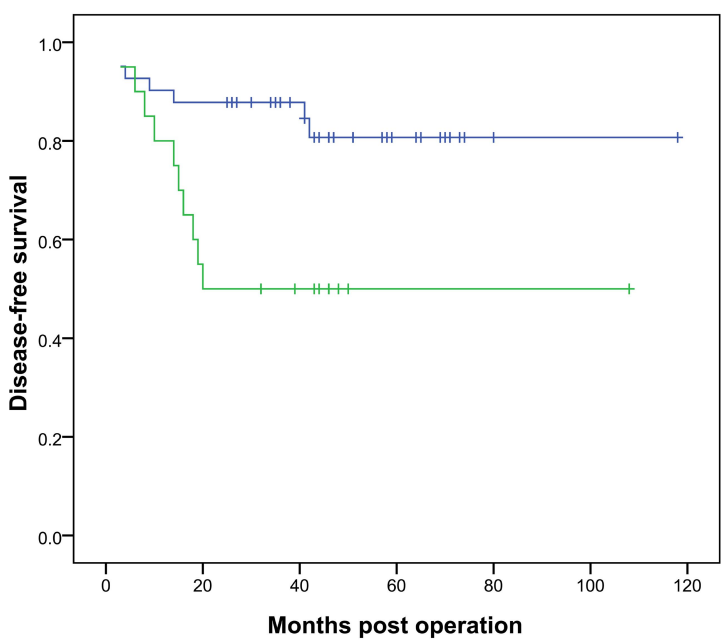

Survival Functions

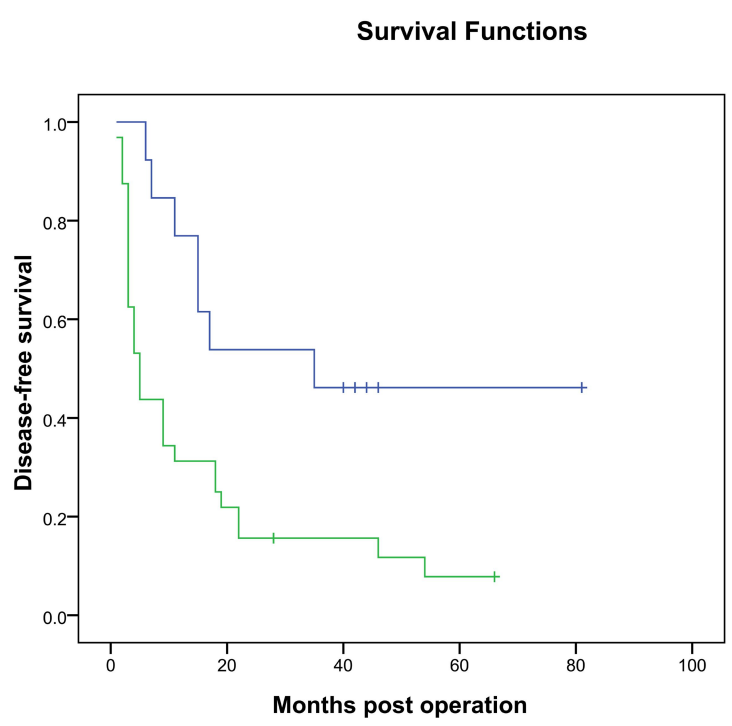

Survival Functions

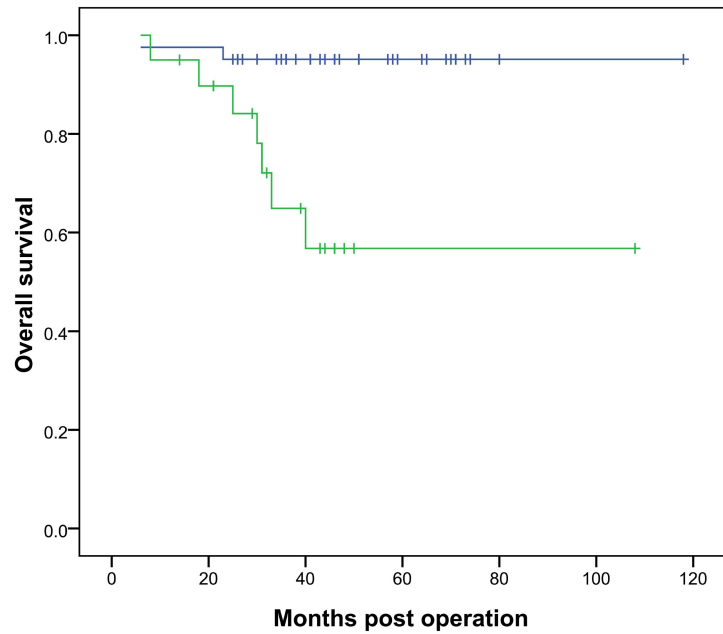

tumor size $\leq 5 \mathrm{~cm}$ $\neg$ LAPs $\leq 87 \mathrm{U} / \mathrm{L}$ $\neg$ LAPs $>87 \mathrm{U} /$ +0 -censored +1 -censored

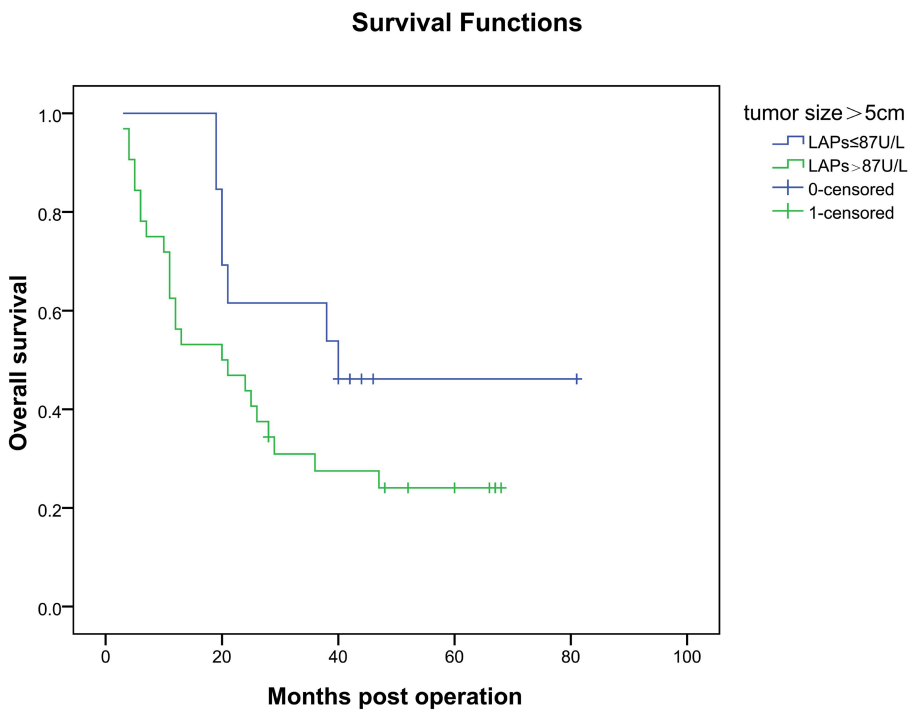

Figure 3 DFS and OS for HCC patients who underwent liver transplantation with the largest tumor size $\leq 5 \mathrm{~cm}$ and $>5 \mathrm{~cm}$ grouped by serum LAP level.

Distinguishing Effect of LAPs in HCC Patients without and with Macro-Vascular Invasion

As for patients without macro-vascular invasion, the 1, 3, 5-year DFS rates were significantly poorer for these with serum LAPs $>87 \mathrm{U} / \mathrm{L}(\mathrm{n}=30)$ than those with serum LAPs $\leq 87 \mathrm{U} / \mathrm{L}(\mathrm{n}=49)(63.3 \%, 46.7 \%, 27.2 \%$ vs $87.8 \%, 83.7 \%$, $80.5 \%, P<0.001)$. And it was the same for patients' OS rates $(80.0 \%, 64.7 \%, 53.1 \%$ vs $98.0 \%, 89.8 \%, 87.2 \%, P=$ 0.002). For patients with macro-vascular invasion, the 1,3 , 5 -year DFS and OS were poorer for these with serum LAPs $>87 \mathrm{U} / \mathrm{L}(\mathrm{n}=22)$ than those with serum LAPs $\leq 87 \mathrm{U} / \mathrm{L}(\mathrm{n}$ $=5)$, but not statistically significant $(31.8 \%, 4.5 \%, 0$ vs
$80.0 \%, 20.0 \%, 0$ for $1,3,5$-year DFS rates, $P=0.136$ ). And it was the same for patients' OS rates (59.1\%, 13.6\%, 0 vs $100 \%, 60.0 \%, 30.0 \%$ for $1,3,5$-year OS, $P=0.162$ ) (Supplement Figure 2). Serum LAPs could be a prognostic marker for patients without macro-vascular invasion, but not for patients with macro-vascular invasion.

\section{Distinguishing Effect of LAPs in HCC Patients without and with Micro-Vascular Invasion}

As for patients without micro-vascular invasion, the 1, 3, 5-year DFS rates were significantly poorer for these with serum LAPs $>87 \mathrm{U} / \mathrm{L}(\mathrm{n}=42)$ than those with 
Survival Functions

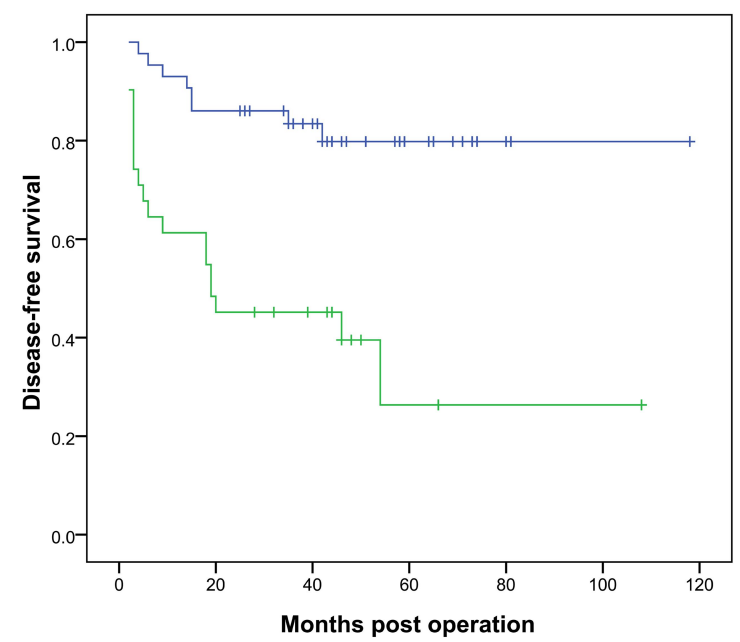

Survival Functions

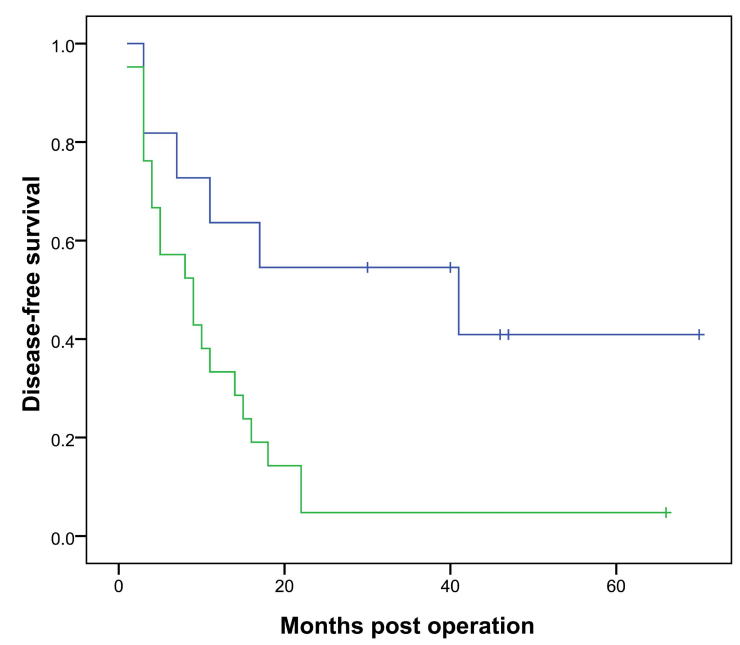

Survival Functions

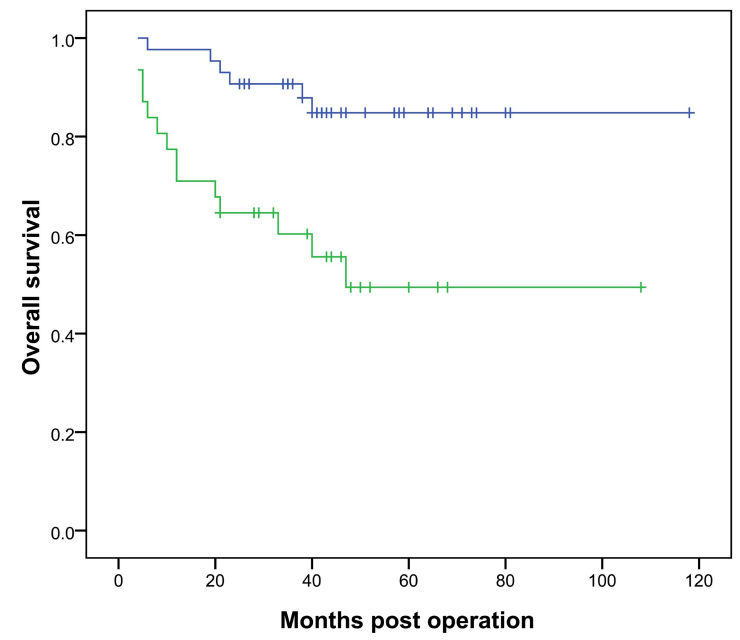

Survival Functions

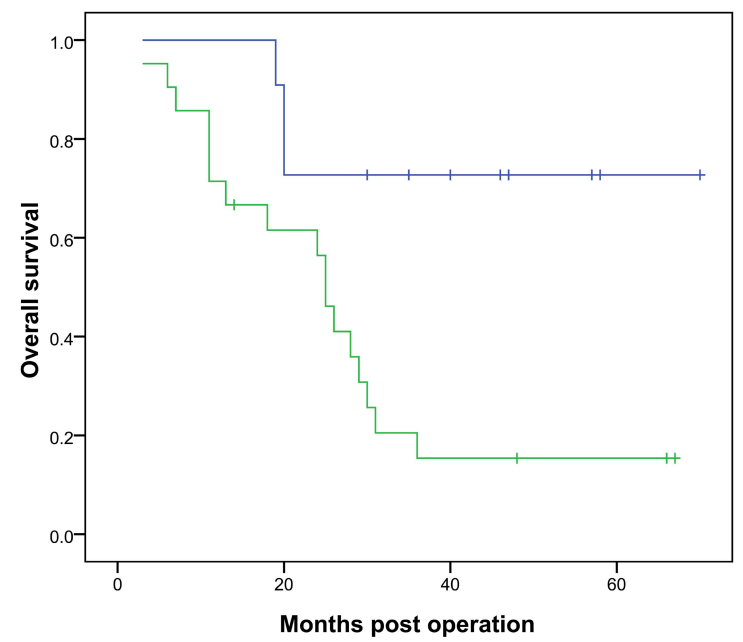

tumor number $\leq 3$ $\neg L_{A P s} \leq 87 \mathrm{U} / L$ $\neg$ LAPs $>87 \mathrm{U} / \mathrm{L}$ +0 -censored
+1 -censored

Figure 4 DFS and OS for HCC patients who underwent liver transplantation with tumor number $\leq 3$ and $>3$ grouped by serum LAP level.

serum LAPs $\leq 87 \mathrm{U} / \mathrm{L}(\mathrm{n}=51)(54.8 \%, 33.3 \%, 29.2 \%$ vs $88.2 \%, 80.4 \%, 77.7 \%, P<0.001)$. And it was the same for patients' OS rates $(73.8 \%, 47.5 \%, 39.7 \%$ vs $98.0 \%, 88.2 \%, 85.6 \%, P<0.001)$. For patients with micro-vascular invasion, the 1, 3, 5-year DFS and OS rates were poorer for these with serum LAPs $>87 \mathrm{U} / \mathrm{L}$ $(\mathrm{n}=10)$ than those with serum LAPs $\leq 87 \mathrm{U} / \mathrm{L}(\mathrm{n}=3)$, but not statistically significant $(30.0 \%, 10.0 \%, 10.0 \%$ vs $66.7 \%, 33.3 \%, 0$ for $1,3,5$-year DFS, $P=0.292)$. And it was the same for patients' OS rates $(60.0 \%, 20.0 \%$, $20.0 \%$ vs $100 \%, 66.7 \%, 33.1 \%$ for $1,3,5$-year OS rates, $P=0.425)$ (Supplement Figure 3).

\section{Distinguishing Effect of LAPs in HCC Patients Within and Beyond Selection Criteria}

Serum LAPs had been demonstrated to be a prognostic marker for patients with different AFP level, tumor number, tumor size $\leq 5 \mathrm{~cm}$, no macro-vascular invasion and no microvascular invasion. Then, we investigated the prognostic value of serum LAPs in patients within and beyond three well accepted criteria, Milan criteria, UCSF criteria and Hangzhou criteria, all of which were combinations of tumor size, tumor number, tumor size and AFP level. For patients 
who met Milan criteria, the 1,3,5-year DFS rates for these with serum LAPs $>87 \mathrm{U} / \mathrm{L}(\mathrm{n}=7)$ were significantly poorer than those with serum LAPs $\leq 87 \mathrm{U} / \mathrm{L}(\mathrm{n}=30)(71.4 \%, 57.1 \%$, $57.1 \%$ vs $96.7 \%, 96.7 \%, 91.3 \%, P=0.007)$, which were also the same for patients beyond Milan criteria. The 1, 3, 5-year DFS rates for patients with serum LAPs $>87 \mathrm{U} / \mathrm{L}(\mathrm{n}=45)$ were significantly poorer than patients with serum LAPs $\leq 87$ $\mathrm{U} / \mathrm{L}(\mathrm{n}=24)(46.7 \%, 24.4 \%, 14.0 \%$ vs $75.0 \%, 53.5 \%, 47.5 \%$, $P=0.010)$. For patients who met UCSF criteria, the 1,3 , 5 -year DFS rates for these with serum LAPs $>87 \mathrm{U} / \mathrm{L}(\mathrm{n}=17)$ were poorer than those with serum LAPs $\leq 87 \mathrm{U} / \mathrm{L}(\mathrm{n}=39)$, but not statistically significant $(82.4 \%, 70.6 \%, 70.6 \%$ vs $94.9 \%, 86.8 \%, 82.7 \%, P=0.188)$, which may due to a relative small difference between the groups and limited patients enrolled. However, for patients beyond UCSF criteria, the 1,3,5-year DFS rates for these with serum LAPs $>87 \mathrm{U} / \mathrm{L}$ $(\mathrm{n}=35)$ were significantly poorer than those with serum LAPs $\leq 87 \mathrm{U} / \mathrm{L}(\mathrm{n}=15)(34.3 \%, 8.6 \%, 2.9 \%$ vs $66.7 \%, 53.3 \%$, $44.4 \%, P=0.002)$. For patients within and beyond Hangzhou criteria, the 1, 3, 5-year DFS rates were significantly poorer for these with serum LAPs $>87 \mathrm{U} / \mathrm{L}$ than those with serum LAPs $\leq 87 \mathrm{U} / \mathrm{L}$. For patients who met Hangzhou criteria, the 1, 3, 5-DFS rates were $76.2 \%, 61.9 \%, 41.3 \%$ and $88.9 \%, 86.7 \%$, $83.2 \%$ for patients with serum LAPs $>87 \mathrm{U} / \mathrm{L}(\mathrm{n}=21)$ and $\leq$ $87 \mathrm{U} / \mathrm{L}(\mathrm{n}=45)$, separately. For patients beyond Hangzhou criteria, which were $32.3 \%, 6.5 \%, 3.2 \%$ and $77.8 \%, 33.3 \%$, $16.7 \%$ for patients with serum LAPs $>87 \mathrm{U} / \mathrm{L}(\mathrm{n}=31)$ and $\leq$ $87 \mathrm{U} / \mathrm{L}(\mathrm{n}=9)$, separately, the $P$ values were 0.015 and 0.034

(Figure 5) (Supplementary Table 3).

\section{Discussion}

We demonstrated, for the first time, that serum LAPs could be an important prognostic marker for HCC patients who underwent LT. These patients with elevated serum LAPs ( $>87 \mathrm{U} / \mathrm{L})$ showed a higher rate of tumor recurrence and shorter lifespan, and further investigation indicated that there was negative correlation, to some extent, between serum LAP level and HCC patients' prognosis both on DFS and OS. It was also found that patients with serum LAPs $>87 \mathrm{U} / \mathrm{L}$ tended to have higher serum AFP level, larger tumor size, more tumor nodules and higher rate of macro-vascular invasion, which were all related to poor prognosis. Multivariate analysis revealed that serum LAPs $>87 \mathrm{U} / \mathrm{L}$, accompanied by the largest tumor size $>5 \mathrm{~cm}$ and macro-vascular invasion, was an independent risk factor for prognosis both on DFS and OS. Serum LAPs also showed a distinguishing effect in patients with different status of AFP level, tumor number, the largest tumor size $\leq 5 \mathrm{~cm}$, no macro-vascular invasion and no microvascular invasion. As for patients who met the criteria of Milan, UCSF and Hangzhou criteria, the prognosis both on DFS and OS of patients with LAPs $\leq 87 \mathrm{U} / \mathrm{L}$ was significantly better than those with LAPs $>87 \mathrm{U} / \mathrm{L}$, except for patients who met the criteria of USCF.

The exact mechanism of LAPs on tumor malignancy had been investigated. As previously described, LAPs contained many subsets, leucine aminopeptidase 3, a member of LAPs from the peptidase M17 family, whose expression was significantly up-regulated in HCC tissues and cell lines compared with normal liver tissues and human hepatocyte cell line, separately. ${ }^{26}$ LAP3 promoted HCC cell line proliferation by regulating the G1/S checkpoint in the cell cycle and facilitate cell migration, which were correlated with lower differentiation, positive lymph node metastasis, high Ki-67 expression and a poor OS rate in HCC patients. ${ }^{26}$ It was also demonstrated in ovarian cancer cells that LAP3 regulated P38 MAPK/ Hsp27 and PI3K/Akt pathways and was associated with the expression of fascin and MMP-2/9 protein, which played important roles in tumor cell migration and extracellular matrix degradation. ${ }^{30}$ As for human gliomas, increased LAP3 expression was associated with the tumor degrading and poor OS, and could facilitate glioma cell viability, proliferation, migration and invasion in vitro. ${ }^{31}$ Similar results were found in patients with esophageal squamous cell carcinoma and cell lines. ${ }^{32}$

Other subsets of LAPs, aminopeptidase N (APN or CD13) and adipocyte-derived leucine aminopeptidase/ puromycin insensitive leucyl-specific aminopeptidase, members of LAPs from the peptidase M1 family, were reported to participate in angiogenesis, which may partially explain the high incidence of macro-vascular invasion in patients with higher serum LAP level. APN/CD13 had been reported to be associated with extracellular matrix degradation and thus to facilitate tumor invasion. ${ }^{33,34}$ Immunohistochemical staining showed that APN was expressed in the vasculature of carcinoma both in human and experimental animals and in corpus luteum undergoing angiogenesis, as was negative in blood vessels of normal tissues. ${ }^{35}$ Both APN antibodies and leucine aminopeptidase inhibitor could inhibit neovascularization and tumor growth. ${ }^{35}$ Further investigation showed that the RAS/MAPK pathway and phosphatidylinositol-3 kinase were involved in the induction of CD13/APN expression in response to angiogenic growth 
Survival Functions

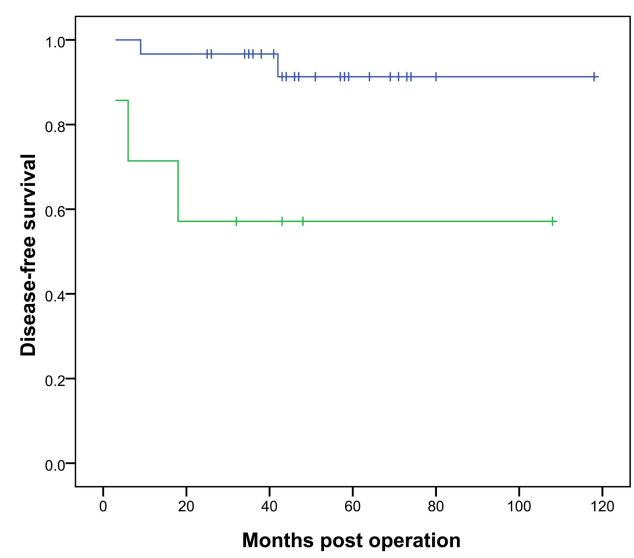

Survival Functions

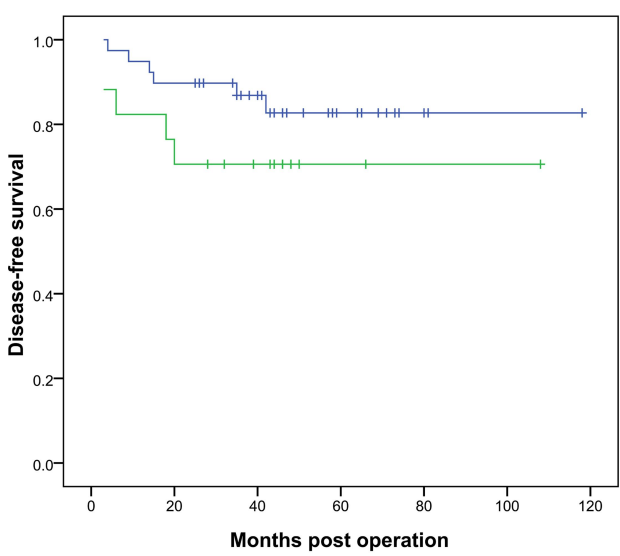

Survival Functions

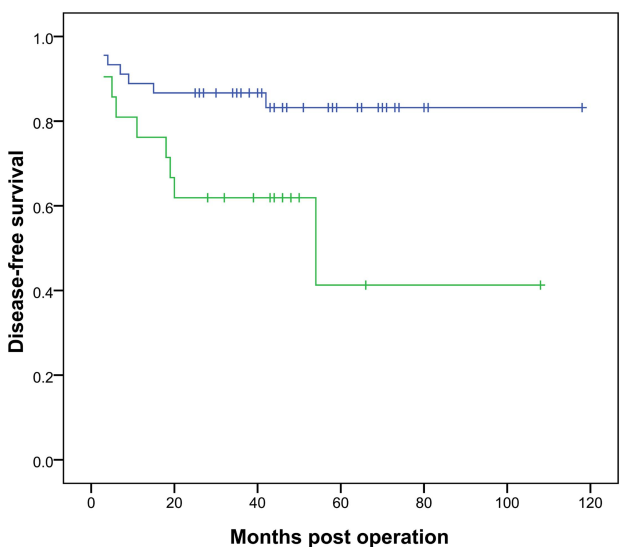

Survival Functions

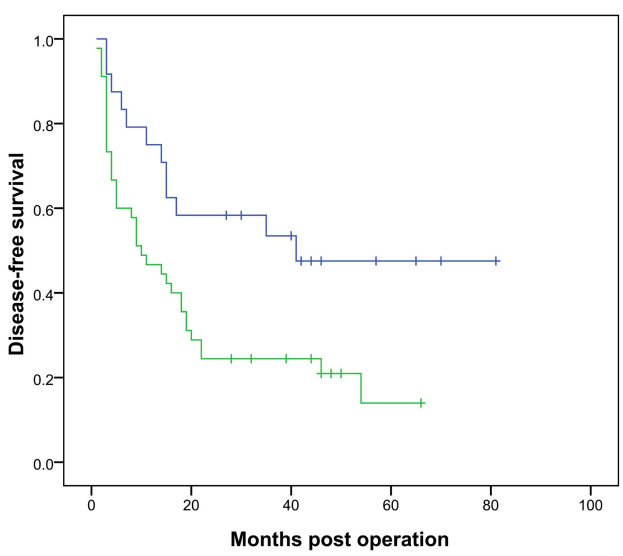

Survival Functions

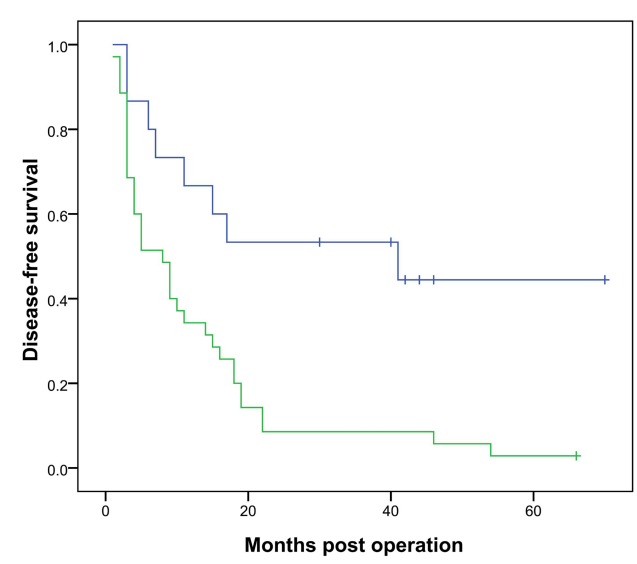

Survival Functions

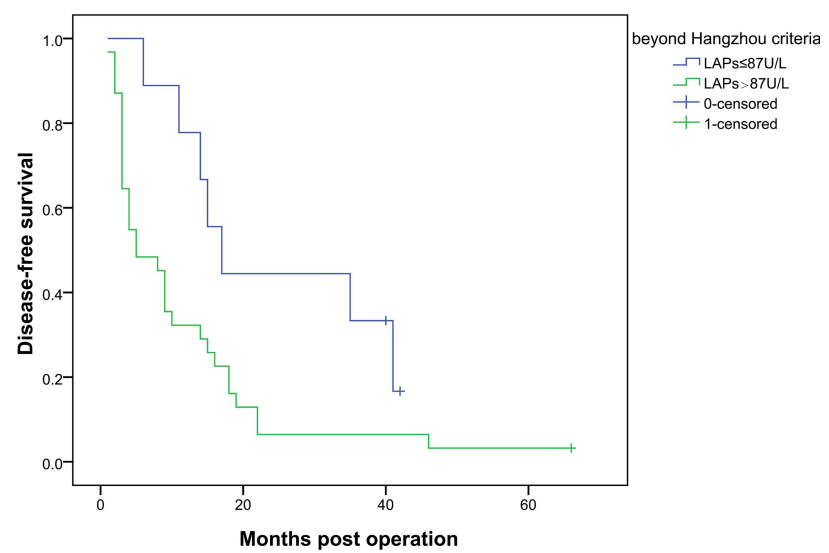

Figure 5 DFS for HCC patients who underwent liver transplantation within and beyond selection criteria grouped by serum LAP level.

factors through up-regulation of CD13/APN promoter activity. ${ }^{36,37}$ The proto-oncogene c-Maf could also potently activate transcription of the $\mathrm{CD} 13$ through directly binding the -153 bp promoter region. ${ }^{38}$
A mouse orthologue of PILSAP, another type of LAP, had been demonstrated to be expressed in endothelial cells during postnatal angiogenesis and be of importance in angiogenesis both in vitro and in vivo. ${ }^{39}$ 
Besides, placental leucine aminopeptidase (P-LAP), also a member of leucine aminopeptidases from the aminopeptidase M1 family, is membrane-bound and transported through vesicles, which could be cleaved proteolytically by metalloproteases and form the serum P-LAP. P-LAP, distributed widely in human tissues, other than being limited to the placenta only, which participated in physiological activities, such as pregnancy, ${ }^{40}$ diabetes ${ }^{41}$ and blood pressure, ${ }^{42}$ had also been reported to be involved in malignancy. ${ }^{43}$ In patients with endometrial carcinoma, tissue expression of P-LAP could serve as an independent prognostic marker of clinical outcome, and was positively associated with tumor histological grade, surgical stage, myometrial invasion, lymph node involvement, vascular infiltration and poor disease-free interval. ${ }^{44}$ Similar results were also found in rat breast cancer tissues. ${ }^{45}$

All of these research studies mentioned above were focused on tissue and cell LAP expression, and serum LAPs could be cell-derived enzymes with or without molecular aggregates. ${ }^{24}$ Elevated serum LAPs in HCC patients have been reported by investigators domestic and abroad, ${ }^{27,46,47}$ which also could serve as a tumor marker in $\mathrm{HCC}$ diagnosis ${ }^{27}$ and differentiation from secondary hepatocarcinoma, ${ }^{47}$ but its prognostic value in $\mathrm{HCC}$ patients who underwent LT was not yet reported. Besides HCC, serum LAP elevation was also found in patients with chronic granulocytic leukemia, acute myelocytic leukemia, myelofibrosis, lymphosarcoma and malignant melanoma. ${ }^{24}$ As for patients enrolled in the study, none of these diseases coexisted.

There were several limitations for this study; as a routine biochemical test, we evaluated the total activity of LAPs without further tests of its subsets. No specific subsets of LAPs were tested either in serum or hepatocellular carcinoma tissues. There were also other shortages, such as the small enrolled population, certain proportion of data censored, less convincing than prospective studies due to the nature of its retrospective analysis and potentially confounding factors caused by donor characteristics. However, due to its ethical reason, a prospective study may not be available until more evidence based on an enlarged HCC population from multiple liver transplantation centers confirms the prognostic value of LAP.

In conclusion, serum LAPs could be a prognostic marker for HCC patients who underwent LT, and patients with elevated serum LAPs tended to have higher AFP level, larger tumor size, more tumor nodules, more macrovascular invasion and thus a poor outcome both on DFS and OS. Further investigation revealed a negative correlation between serum LAP level and patients' DFS and OS. Serum LAPs could be used to screen patients more suitable for LT and with high risk of tumor recurrence both within and beyond the three well known criteria, except for patients within UCSF criteria. The exact mechanism of serum LAPs or its subset on tumor malignancy and HCC patients' prognosis is still in need of further investigation.

\section{Abbreviations}

LAPs, leucine aminopeptidases; HCC, hepatocellular carcinoma; LT, liver transplantation; AFP, alpha-fetoprotein; DFS, disease-free survival; OS, overall survival; UCSF, University of California, San Francisco; ROC curve, receiver operating characteristic curve; APN, aminopeptidase N; P-LAP, placental leucine aminopeptidase.

\section{Data Sharing Statement}

The datasets used and/or analyzed during the current study are available from the corresponding author Weiqiang $\mathrm{Ju}$ on reasonable request.

\section{Ethics and Consent Statement}

The study was approved by the medical ethic committee of the First Affiliated Hospital, Sun Yat-sen University, and due to the retrospective nature of the study, written informed consent was waived.

\section{Consent for Publication}

Written informed consent for publication was obtained.

\section{Author Contributions}

All authors made substantial contributions to conception and design, acquisition of data, or analysis and interpretation of data; took part in drafting the article or revising it critically for important intellectual content; agreed to submit to the current journal; gave final approval of the version to be published; and agree to be accountable for all aspects of the work.

\section{Funding}

This study was supported by the Guangdong Provincial Key Laboratory Construction Projection on Organ Donation and Transplant Immunology (2013A061401007), the Guangdong Provincial international Cooperation Base of Science and Technology (Organ Transplantation) (2015B050501002), the Science and Technology Planning Project of Guangzhou City (201605131229503), the Science and Technology Planning 
Project of Guangdong Province (2013B040200019), the Special Foundation for Science and Technology Development of Guangdong Province (2017B090904010), the Science, Technology and Innovation Commission of Shenzhen Municipality (JCYJ20190809095801653, JCYJ20190809100217290), the Sanming Project of Medicine in Shenzhen (SZSM201612021) and the Scientific Research Project of Health and Family Planning Commission of Shenzhen Municipality (SZXJ2018086).

\section{Disclosure}

The authors have no conflicts of interest to declare.

\section{References}

1. Global Burden of Disease Cancer C, Fitzmaurice C, Dicker D, et al. The global burden of cancer 2013. JAMA Oncol. 2015;1(4):505-527. doi:10.1001/jamaoncol.2015.0735

2. Jelic S, Sotiropoulos GC, Group EGW. Hepatocellular carcinoma: ESMO clinical practice guidelines for diagnosis, treatment and follow-up. Ann Oncol. 2010;21(Suppl 5):v59-v64. doi:10.1093/ annonc/mdq166

3. Verslype C, Rosmorduc O, Rougier P, Group EGW. Hepatocellular carcinoma: ESMO-ESDO clinical practice guidelines for diagnosis, treatment and follow-up. Ann Oncol. 2012;23(Suppl 7):vii41-vii48. doi:10.1093/annonc/mds225

4. Cha C, Fong Y, Jarnagin WR, Blumgart LH, DeMatteo RP. Predictors and patterns of recurrence after resection of hepatocellular carcinoma. J Am Coll Surg. 2003;197(5):753-758. doi:10.1016/j. jamcollsurg.2003.07.003

5. Angus PW, McCaughan GW, Gane EJ, Crawford DH, Harley H. Combination low-dose hepatitis B immune globulin and lamivudine therapy provides effective prophylaxis against posttransplantation hepatitis B. Liver Transpl. 2000;6(4):429-433. doi:10.1053/ jlts. 2000.8310

6. Kaido T, Morita S, Tanaka S, et al. Long-term outcomes of hepatic resection versus living donor liver transplantation for hepatocellular carcinoma: a propensity score-matching study. Dis Markers. 2015;2015:425926. doi:10.1155/2015/425926

7. Chapman WC, Klintmalm G, Hemming A, et al. Surgical treatment of hepatocellular carcinoma in North America: can hepatic resection still be justified? J Am Coll Surg. 2015;220(4):628-637. doi:10.1016/ j.jamcollsurg.2014.12.030

8. Wong RJ, Wantuck J, Valenzuela A, et al. Primary surgical resection versus liver transplantation for transplant-eligible hepatocellular carcinoma patients. Dig Dis Sci. 2014;59(1):183-191. doi:10.1007/ s10620-013-2947-8

9. Zheng Z, Liang W, Milgrom DP, et al. Liver transplantation versus liver resection in the treatment of hepatocellular carcinoma: a meta-analysis of observational studies. Transplantation. 2014;97 (2):227-234. doi:10.1097/TP.0b013e3182a89383

10. Mazzaferro V, Regalia E, Doci R, et al. Liver transplantation for the treatment of small hepatocellular carcinomas in patients with cirrhosis. $N$ Engl $J$ Med. 1996;334(11):693-699. doi:10.1056/ NEJM199603143341104

11. Yao FY, Ferrell L, Bass NM, et al. Liver transplantation for hepatocellular carcinoma: expansion of the tumor size limits does not adversely impact survival. Hepatology. 2001;33(6):1394-1403. doi:10.1053/jhep.2001.24563
12. Zheng SS, Xu X, Wu J, et al. Liver transplantation for hepatocellular carcinoma: Hangzhou experiences. Transplantation. 2008;85 (12):1726-1732. doi:10.1097/TP.0b013e31816b67e4

13. Toso C, Asthana S, Bigam DL, Shapiro AM, Kneteman NM. Reassessing selection criteria prior to liver transplantation for hepatocellular carcinoma utilizing the scientific registry of transplant recipients database. Hepatology. 2009;49(3):832-838. doi:10.1002/ hep. 22693

14. Hong G, Suh KS, Suh SW, et al. Alpha-fetoprotein and (18)F-FDG positron emission tomography predict tumor recurrence better than milan criteria in living donor liver transplantation. $J$ Hepatol. 2016;64(4):852-859. doi:10.1016/j.jhep.2015.11.033

15. Cheung TT, Ho CL, Lo CM, et al. 11C-acetate and 18F-FDG PET/ CT for clinical staging and selection of patients with hepatocellular carcinoma for liver transplantation on the basis of milan criteria: surgeon's perspective. $J$ Nucl Med. 2013;54(2):192-200. doi:10.2967/jnumed.112.107516

16. Chen CL, Cheng YF, Yu CY, et al. Living donor liver transplantation: the Asian perspective. Transplantation. 2014;97(Suppl 8):S3. doi:10.1097/TP.0000000000000060

17. Mazzaferro V, Llovet JM, Miceli R, et al. Predicting survival after liver transplantation in patients with hepatocellular carcinoma beyond the Milan criteria: a retrospective, exploratory analysis. Lancet Oncol. 2009;10(1):35-43. doi:10.1016/S1470-2045(08)70284-5

18. Fernandez JA, Robles R, Marin C, et al. Can we expand the indications for liver transplantation among hepatocellular carcinoma patients with increased tumor size? Transplant Proc. 2003;35 (5):1818-1820. doi:10.1016/S0041-1345(03)00723-1

19. Duvoux C, Roudot-Thoraval F, Decaens T, et al. Liver transplantation for hepatocellular carcinoma: a model including alpha-fetoprotein improves the performance of milan criteria. Gastroenterology. 2012;143(4):98694e3; quiz e14-e15. doi:10.1053/j.gastro.2012.05.052

20. Rawlings ND, Barrett AJ. Handbook of Proteolytic Enzymes Introduction: Metallopeptidases and Their Clans. 2nd ed. Elsevier/ Academic Press; 2004:231-268.

21. Matsui M, Fowler JH, Walling LL. Leucine aminopeptidases: diversity in structure and function. Biol Chem. 2006;387(12):1535-1544. doi:10.1515/BC.2006.191

22. Smith EL, Hill RL. The Enzymes: Leucine Aminopeptidase. Vol. 4. Academic Press, Inc; 1960:37-62.

23. Huang H, Tanaka H, Hammock BD, Morisseau C. Novel and highly sensitive fluorescent assay for leucine aminopeptidases. Anal Biochem. 2009;391(1):11-16. doi:10.1016/j.ab.2009.05.004

24. Phillips RW, Manildi ER. Elevation of leucine aminopeptidase in disseminated malignant disease. Cancer. 1970;26(5):1006-1012. doi:10.1002/1097-0142(197011)26:5<1006::aid-cncr2820260507>3. $0 . c o ; 2-\mathrm{i}$

25. Kohno H, Kanda S, Kanno T. Immunoaffinity purification and characterization of leucine aminopeptidase from human liver. J Biol Chem. 1986;261(23):10744-10748. doi:10.1016/S0021-9258(18)67448-4

26. Tian S-Y, Chen S-H, Shao B-F, et al. Expression of leucine aminopeptidase 3 (LAP3) correlates with prognosis and malignant development of human hepatocellular carcinoma (HCC). Int J Clin Exp Pathol. 2014;7(7):3752-3762.

27. Abouzied MM, Eltahir HM, Fawzy MA, et al. Estimation of leucine aminopeptidase and 5-nucleotidase increases alpha-fetoprotein sensitivity in human hepatocellular carcinoma cases. Asian Pac J Cancer Prev. 2015;16(3):959-963. doi:10.7314/apjcp.2015.16.3.959

28. Ren QQ, Fu SJ, Zhao Q, et al. Prognostic value of preoperative peripheral monocyte count in patients with hepatocellular carcinoma after liver transplantation. Tumour Biol. 2016;37(7):8973-8978. doi:10.1007/s13277-015-4758-3

29. Grandhi MS, Kim AK, Ronnekleiv-Kelly SM, Kamel IR, Ghasebeh MA, Pawlik TM. Hepatocellular carcinoma: from diagnosis to treatment. Surg Oncol. 2016;25(2):74-85. doi:10.1016/j.suronc. 2016.03.002 
30. Wang X, Shi L, Deng Y, et al. Inhibition of leucine aminopeptidase 3 suppresses invasion of ovarian cancer cells through down-regulation of fascin and MMP-2/9. Eur J Pharmacol. 2015;768:116-122. doi:10.1016/j.ejphar.2015.10.039

31. He X, Huang Q, Qiu X, et al. LAP3 promotes glioma progression by regulating proliferation, migration and invasion of glioma cells. Int $J$ Biol Macromol. 2015;72:1081-1089. doi:10.1016/j. ijbiomac.2014.10.021

32. Zhang S, Yang X, Shi H, et al. Overexpression of leucine aminopeptidase 3 contributes to malignant development of human esophageal squamous cell carcinoma. J Mol Histol. 2014;45(3):283-292. doi:10.1007/s10735-014-9566-3

33. Saiki I, Fujii H, Yoneda J, et al. Role of aminopeptidase N (CD13) in tumor-cell invasion and extracellular matrix degradation. Int J Cancer. 1993;54(1):137-143. doi:10.1002/ijc.2910540122

34. Fontijn D, Duyndam MC, van Berkel MP, et al. CD13/aminopeptidase $\mathrm{N}$ overexpression by basic fibroblast growth factor mediates enhanced invasiveness of 1F6 human melanoma cells. Br J Cancer. 2006;94(11):1627-1636. doi:10.1038/sj.bjc.6603157

35. Pasqualini R, Koivunen E, Kain R, et al. Aminopeptidase N is a receptor for tumor-homing peptides and a target for inhibiting angiogenesis. Cancer Res. 2000;60(3):722-727.

36. Bhagwat SV, Lahdenranta J, Giordano R, Arap W, Pasqualini R, Shapiro LH. CD13/APN is activated by angiogenic signals and is essential for capillary tube formation. Blood. 2001;97(3):652-659. doi:10.1182/blood.v97.3.652

37. Bhagwat SV, Petrovic N, Okamoto Y, Shapiro LH. The angiogenic regulator CD13/APN is a transcriptional target of ras signaling pathways in endothelial morphogenesis. Blood. 2003;101(5):1818-1826. doi:10.1182/blood-2002-05-1422

38. Mahoney KM, Petrovic N, Schacke W, Shapiro LH. CD13/APN transcription is regulated by the proto-oncogene c-maf via an atypical response element. Gene. 2007;403(1-2):178-187. doi:10.1016/j. gene.2007.08.010

39. Miyashita H, Yamazaki T, Akada T, et al. A mouse orthologue of puromycin-insensitive leucyl-specific aminopeptidase is expressed in endothelial cells and plays an important role in angiogenesis. Blood. 2002;99(9):3241-3249. doi:10.1182/blood.v99.9.3241
40. Nomura S, Ito T, Yamamoto E, et al. Gene regulation and physiological function of placental leucine aminopeptidase/oxytocinase during pregnancy. Biochim Biophys Acta. 2005;1751(1):19-25. doi:10.1016/j.bbapap.2005.04.006

41. Keller SR. Role of the insulin-regulated aminopeptidase IRAP in insulin action and diabetes. Biol Pharm Bull. 2004;27(6):761-764. doi:10.1248/bpb.27.761

42. Tsujimoto M, Goto Y, Maruyama M, Hattori A. Biochemical and enzymatic properties of the M1 family of aminopeptidases involved in the regulation of blood pressure. Heart Fail Rev. 2008;13 (3):285-291. doi:10.1007/s10741-007-9064-8

43. Mizutani S, Shibata K, Kikkawa F, et al. Essential role of placental leucine aminopeptidase in gynecologic malignancy. Expert Opin Ther Targets. 2007;11(4):453-461. doi:10.1517/14728222.11.4.453

44. Shibata K, Kikkawa F, Suzuki Y, et al. Expression of placental leucine aminopeptidase is associated with a poor outcome in endometrial endometrioid adenocarcinoma. Oncology. 2004;66 (4):288-295. doi:10.1159/000078329

45. Pilar Carrera M, Ramirez-Exposito MJ, Duenas B, et al. Insulinregulated aminopeptidase/placental leucil aminopeptidase (IRAP/ P-lAP) and angiotensin IV-forming activities are modified in serum of rats with breast cancer induced by N-methyl-nitrosourea. Anticancer Res. 2006;26(2A):1011-1014.

46. Boliang W, Zhong Y, Gu B, Cao Y, Lu J, Xiaoxi T. Application of leucine aminopeptidase in the diagnosis of hepatic diseases. J Fourth Mil Med Univ. 2003;24(9):844-845.

47. Abdel-Hamid NM, Abouzied MM, Nazmy MH, Fawzy MA, Gerges AS. A suggested guiding panel of seromarkers for efficient discrimination between primary and secondary human hepatocarcinoma. Tumour Biol. 2016;37(2):2539-2546. doi:10.1007/ s13277-015-4025-7

\section{Publish your work in this journal}

Cancer Management and Research is an international, peer-reviewed open access journal focusing on cancer research and the optimal use of preventative and integrated treatment interventions to achieve improved outcomes, enhanced survival and quality of life for the cancer patient.
The manuscript management system is completely online and includes a very quick and fair peer-review system, which is all easy to use. Visit http://www.dovepress.com/testimonials.php to read real quotes from published authors. 